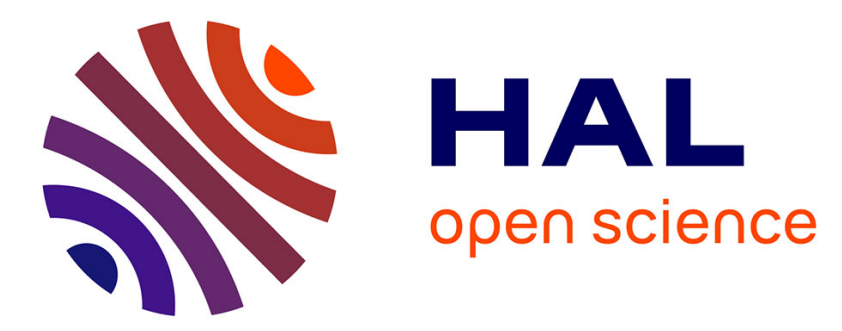

\title{
Consensus statement on the management of dyslipidaemias in adults
}

\author{
S. Beliard, F. Bonnet, B. Bouhanick, E. Bruckert, B. Cariou, S. Charrière, V. \\ Durlach, P. Moulin, Rene Valero, B. Vergès
}

\section{- To cite this version:}

S. Beliard, F. Bonnet, B. Bouhanick, E. Bruckert, B. Cariou, et al.. Consensus statement on the management of dyslipidaemias in adults. Annales d'Endocrinologie, 2017, 78 (1), pp.43 - 53. 10.1016/j.ando.2016.11.001 . hal-01757613

\section{HAL Id: hal-01757613 https://hal-amu.archives-ouvertes.fr/hal-01757613}

Submitted on 10 Apr 2018

HAL is a multi-disciplinary open access archive for the deposit and dissemination of scientific research documents, whether they are published or not. The documents may come from teaching and research institutions in France or abroad, or from public or private research centers.
L'archive ouverte pluridisciplinaire HAL, est destinée au dépôt et à la diffusion de documents scientifiques de niveau recherche, publiés ou non, émanant des établissements d'enseignement et de recherche français ou étrangers, des laboratoires publics ou privés. 


\title{
Consensus statement on the management of dyslipidaemias in adults ${ }^{\text {is }}$
}

\author{
Working group commissioned by the the French Society of Endocrinology (SFE) Francophone \\ Society of Diabetes (SFD), The New French Society of Atherosclerosis (NSFA), S. Béliard ${ }^{\text {a }}$,

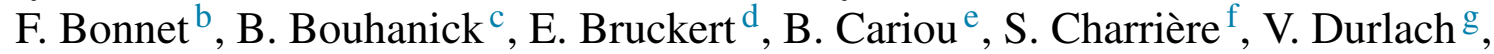 \\ P. Moulin ${ }^{\mathrm{f}, *}, \mathrm{R}$. Valéro ${ }^{\mathrm{a}}, \mathrm{B}$. Vergès $\mathrm{g}, \mathrm{h}$ \\ ${ }^{a}$ Service de nutrition, maladies métaboliques, endocrinologie, hôpital de la Conception, CHU de Marseille, AP-HM, 13009 Marseille, France \\ b Service d'endocrinologie-diabétologie, Inserm U1018, université Rennes 1, CHU de Rennes, Rennes, France \\ ${ }^{\text {c } P o ̂ l e ~ C V M, ~ s e r v i c e ~ d ' H T A ~ e t ~ t h e ́ r a p e u t i q u e, ~ C H U ~ R a n g u e i l, ~ u n i v e r s i t e ́ ~ d e ~ T o u l o u s e ~ 3, ~} 331059$ Toulouse, France \\ d Service d'endocrinologie, hôpital Pitié Salpêtrière, Paris, France \\ e Inserm UMR 1087, clinique d'endocrinologie, Institut du thorax, université de Nantes, CHU de Nantes, 44000 Nantes, France \\ ${ }^{\mathrm{f}}$ Fédération d'endocrinologie, GHE, HCL, université de Lyon 1, Inserm UMR 1060 CARMEN, 60003 Lyon, France \\ ${ }^{g}$ Pôle thoracique cardiovasculaire et neurologique, hôpital Robert-Debré, 51092 Reims, France \\ ${ }^{\mathrm{h}}$ Service d'endocrinologie, diabétologie et maladies métaboliques, CHU de dijon, INSERM LNC UMR 866, \\ Université Bourgogne Franche-Conté, 21000 Dijon, France
}

Keywords: Dyslipidemia; Cardiovascular risk; Statins; Fibrates; Consensus statement; LDLc goal

\section{Introduction}

Most cases of dyslipidaemia increase the risk of ischaemic cardiovascular (CV) complications, while their treatment can reduce $\mathrm{CV}$ morbidity and mortality. There is, therefore, a broad international consensus for promoting treatment, although with some variations in approach. As previous French recommendations for dyslipidaemia treatment date back 10 years, they are no longer up to date and have been retracted. However, the complex and evolving differences between the recommendations of European societies (EAS/ESC) [1-3], the International Atherosclerosis Society (IAS) [4], and national bodies in the US (AHA/ACC) [5,6] and Great Britain (NICE) [7] mean that it has become necessary for practitioners to have an updated consensus statement informed by the latest clinical trials.

Thus, a synthesis integrating features from both American and European recommendations was created. A condensed version for the sake of simplicity is presented here, although readers may refer to the primary source documents via the

\footnotetext{
A French version of this consensus was published in the Revue du praticien (September issue).

* Corresponding author. Fédération d'endocrinologie, hôpital cardiovasculaire Louis-Pradel, GHE, boulevard Pinel, 60003 Lyon, France.

E-mail address: Philippe.moulin@chu-lyon.fr (P. Moulin).
}

references selected by members of the working group (WG). This consensus statement concerns the general population and does not address either familial hypercholesterolaemia [8-10] or diabetic dyslipidaemia $[11,12]$ in detail. This text is consistent with the opinions of the WG, and has been validated by external readers from three of the societies involved and based on data from the literature available up to $2016 .^{1}$

\section{Initial evaluation}

\subsection{Identification of secondary dyslipidaemia}

Secondary dyslipidaemia must be ruled out through investigation of the diseases and treatments that could cause hyperlipidaemia. This involves checking, when appropriate, thyroid-stimulating hormone (TSH), blood glucose, urine protein by dipstick and creatininaemia. Hypothyroidism and cholestasis can induce hypercholesterolaemia; however, the clinical context of cholestasis is generally suggestive. Nephrotic syndromes can cause severe mixed hyperlipidaemia. Diabetes, renal insufficiency and excessive alcohol consumption result

\footnotetext{
${ }^{1}$ Grading the recommendations was done using the HAS scoring system from A to $\mathrm{C}$ for decreasing levels of strength, and from 1 to 3 for quality evaluation of the literature on which it is based.
} 
Table 1

Major cardiovascular risk factors (CVRF) to be considered in subjects with dyslipidaemia.

\section{CVRF}

Age (men $\geq 50$ years, women $\geq 60$ years)

Ischaemic CV family history (men $\leq 55$ years, women $\leq 60$ years)

Current smoker or quit for $<3$ years

Hypertension

$\mathrm{HDLc} \leq 0.40 \mathrm{~g} / \mathrm{L}(\leq 1.0 \mathrm{mmol} / \mathrm{L})$

Type 2 diabetes (or type 1 diabetes for $>15$ years and age $>40$ years)

Renal failure (GFR $<45 \mathrm{~mL} / \mathrm{min},<60 \mathrm{~mL} / \mathrm{min}$ in young adults)

HDLc: high-density lipoprotein cholesterol; GFR: glomerular filtration rate.

in hypertriglyceridaemia. The main treatments that increase low-density lipoprotein cholesterol (LDLc) and, often, triglycerides (TG) are cyclosporin, retinoids, corticosteroids, oral ethinylestradiol, certain antiretrovirals, certain neuroleptics and certain targeted therapies in oncology.

\subsection{Estimation of $C V$ risk}

$\mathrm{CV}$ risk needs to be taken into consideration for adjusting the intensity of primary prevention measures (before the occurrence of atherothrombotic complications). Indeed, the risk/benefit ratio of the treatment and its efficacy (number of persons to be treated to avoid ischaemic complications) depend on the magnitude of the expected benefit. This is based on the level of absolute risk of the individual concerned. Risk-calculation models refer to the multifactorial risk of the general population and not to monogenic primary dyslipidaemias, such as familial hypercholesterolaemia, for which the level of risk is underestimated with general models. Risk-calculation models specific to diabetes patients are also available [13-15].

In practice terms, the $\mathrm{WG}$ recommends risk evaluation of the general population based on SCORE tables, which estimate the risk of ischaemic $\mathrm{CV}$ death at 10 years [adjusted for low-risk European countries, including France, and taking into account high-density lipoprotein cholesterol (HDLc)] [16]. When such tables are not available, the WG suggests pragmatic tallying of the standard cardiovascular risk factors (CVRF) as a substitution method (low CV risk: 0-1 CVRF; intermediate risk: 2 CVRF; high CV risk: $\geq 3$ CVRF).

\subsubsection{Risk factors and markers}

The main CVRF to be taken into consideration in patients with dyslipidaemia are age and gender, family history of $\mathrm{CV}$ disease (first-degree relatives), tobacco use, arterial hypertension, decreases in HDLc, the presence of diabetes and severe to moderate chronic renal failure (CRF), (Table 1). These all contribute to risk estimation and treatment decision-making.

2.2.1.1. Lipid tests. Lipid tests are needed at the baseline assessment for estimating the individual level of risk, and then during follow-up to evaluate the efficacy of treatment to ensure adherence, to motivate patients with respect to dietary and lifestyle measures, and to guide potential treatment
Table 2

Indications for lipoprotein(a) [Lp(a)] assay.

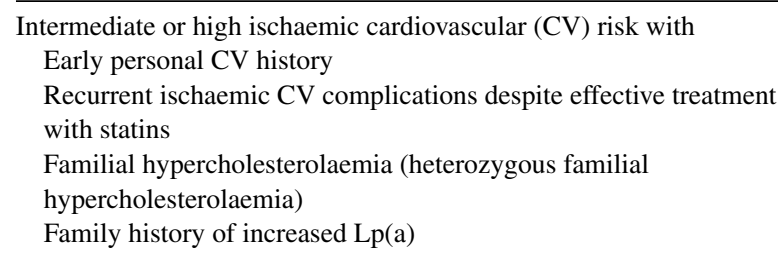

Adapted from Catapano et al. [1], Stone et al. [5] and Nordestgaard [20].

intensification (A1) (Table 1$)^{2}$. It is possible to conduct nonfasting lipid tests when the practitioner finds it necessary to facilitate screening in an elderly person or after an acute coronary syndrome (ACS) [17]. Reliability of the LDLc estimate is all the more affected when there is postprandial hypertriglyceridaemia. Although the role of HDLc as a contributory factor of $\mathrm{CV}$ protection has been called into question, its plasma determination provides a powerful marker of $\mathrm{CV}$ risk and must therefore be maintained in CV risk assessment (A1) [18].

Although no large-scale, double-blind clinical trials have been done with titration of a lipid-lowering treatment to attain an LDLc target, reference markers are necessary for determining the at-risk subject's condition at inclusion and with treatment in relation to levels observed in $\mathrm{CV}$ prevention trials (C3). Cholesterol measurements unrelated to HDL [total cholesterol (TC) - HDLc] may be used in the event of hypertriglyceridaemia (HTG). This takes remnants into account and does not require LDLc assay; its value is $0.3 \mathrm{~g} / \mathrm{L}(0.77 \mathrm{mmol} / \mathrm{L})$ above the usual reference values used for LDLc (B2) [19]. Assay of apolipoprotein $\mathrm{B}(\mathrm{ApoB})$ plasma concentration does not provide major advantages for estimates of $\mathrm{CV}$ risk (B2). Its main clinical relevance is limited to the aetiological diagnosis of mixed hyperlipidaemia to differentiate familial combined hyperlipidaemia from dysbetalipoproteinaemia, in which ApoB is not increased.

Measurement of lipoprotein (a) $[\mathrm{Lp}(\mathrm{a})]$, a risk cofactor for familial hypercholesterolaemia and unexplained atherothrombotic states, should not be done systematically, as its assay indications are restricted (Table 2) [20].

2.2.1.2. Limitations and benefits of other risk markers. The benefits of employing other risk marker assays for clarifying the risk of subjects with dyslipidaemia remain a matter of debate.

2.2.1.2.1. Biological markers. Plasma concentration assays of fibrinogen, ultrasensitive C-reactive protein (us-CRP) [21], homocysteine (excluding unexplained atherothrombotic complications), lipoprotein-associated phospholipase A2 (LpPLA2) [22], lipoparticles (such as LpA1), and the identification of small dense LDL and microalbuminuria (apart from diabetes or hypertension) provide no adequate additional predictive value in dyslipidaemic patients.

2.2.1.2.2. Genotyping. In primary (genetic) hyperlipidaemia, genotyping patients at specialized expert centres enables characterization of the relevant disease (investigation of

\footnotetext{
2 Quotes (A1, B3) correspond to the level of evidence based medicine regarding the recommendation and quality of the literature.
} 
genetic variants of, for example, LDLR, APOB, PCSK9, APOE and LPL) and may soon be used to determine access to specific treatments. However, available studies of the many genetic polymorphisms associated with high CV risk do not substantially improve prediction of $\mathrm{CV}$ risk. Consideration of family history has a more relevant integrative effect at this time $[23,24]$.

2.2.1.3. Functional exploratory studies. In cases of intermediate risk, consideration of additional risk markers indicating premature subclinical atheroma can be used to reclassify subjects into high- or low-risk categories.

2.2.1.3.1. Stress tests. Stress tests do not play a role in estimating $\mathrm{CV}$ risk in the asymptomatic general population. Its indications pertain to monitoring of high- or very high risk patients with either symptomatology suggestive of coronary insufficiency, suspicious electrical abnormalities on baseline ECG or a particularly high probability of silent myocardial ischaemia, as seen in certain subgroups of diabetics. Performance of a stress test is also indicated in the resumption of vigorous physical activity in sedentary subjects with high CV risk.

2.2.1.3.2. Myocardial scintigraphy, stress echo test, dobutamine stress echo tests. These exploratory studies, besides the irradiation and costliness of scintigraphy, are not first-line tests designed to stratify $\mathrm{CV}$ risk through the identification of subclinical coronary insufficiency in asymptomatic dyslipidaemic patients [25].

2.2.1.3.3. Exploratory studies of vascular function. Carotid-femoral pulse wave velocity, in which acceleration indicates arterial rigidity, provides insufficient additional value in terms of reclassifying $\mathrm{CV}$ risk in normotensive dyslipidaemic subjects, although it may be considered relevant in those with hypertension (B2) [26]. Determination of arterial vasodilatation is part of clinical research due to its difficulty and variability. Systematic measurement of the systolic pressure index (SPI) in subjects with low-to-intermediate risk provides an insufficient level of CV risk reclassification $[27,28]$. SPI measurement is a supplementary examination done during Doppler ultrasound for arteriosclerosis obliterans (AO), but is not advisable in dyslipidaemic subjects without a clinical suspicion of $\mathrm{AO}$ (B3).

\subsubsection{Imaging.}

2.2.1.4.1. Carotid ultrasound. Measurement of carotid intima media thickness (IMTc), which is invaluable in clinical research as an integrated marker of risk, has insufficient predictive value in clinical practice for adjusting the prediction of $\mathrm{CV}$ events. Moreover, variability of its measurement due to the method of acquisition and software used hampers comparisons of two separate measurements $[21,29]$. The ability to reclassify ischaemic risk is limited, and its use in clinical practice is not recommended (B2). Detection of significant carotid plaques, however, may be a predictive integration tool and an opportunity to screen for severe carotid stenosis [30,31]. Nevertheless, severe stenosis is rare and usually arises in the context of high $\mathrm{CV}$ risk and/or confirmed polyvascular atheromatous disease. The WG recommends carotid ultrasound with plaque assessment when there is no access to a multislice computed tomography
(CT) scan equipped to measure coronary calcium scoring in intermediate-risk patients (B2).

2.2.1.4.2. Coronary calcium scoring. Quantification of coronary calcifications using a CT scan without contrast injection is a method that uses little irradiation. A very high load of calcified atheromatous plaques suggests the presence of multiple non-calcified plaques (stenotic or non-stenotic); such a finding translates into a level of risk that may be equivalent to that observed in secondary prevention (A1). The results must be interpreted both as an absolute value (very high individual risk when the score exceeds 300-400 AU) and a relative value compared with the score of a similar population to assess the additional relative risk (calcium score $>75 \%$ for age and gender) [32]. A zero score has a strong negative predictive value for $\mathrm{CV}$ ischaemic events. The level of reclassification is high in subjects with intermediate risk [23]. Its use could be effective for optimizing $\mathrm{CV}$ preventative measures in conditions of intermediate risk [33]. The WG recommends its use in this particular situation (B2).

2.2.1.4.3. CT coronary angiography. CT coronary angiography is not indicated in asymptomatic dyslipidaemic patients for assessing subclinical coronary atheroma except for unusual circumstances (C2). However, it may be used in subjects suspected to have stable coronary disease and who are at intermediate risk (B1). A functional test for investigating myocardial ischaemia is generally preferred (A1) [34].

\section{Dietary approaches}

Dietary measures are to be systematically implemented overall for both secondary and primary prevention once LDLc is > $1.3 \mathrm{~g} / \mathrm{L}(3.34 \mathrm{mmol} / \mathrm{L}$, median for French adults) or when serum TG levels are $>1.5 \mathrm{~g} / \mathrm{L}(1.7 \mathrm{mmol} / \mathrm{L}, 90$ th percentile) (A1).

Individualized lifestyle modifications combining physical activity and supervised dietary intakes aimed at nutritional balance and not systematic weight loss [35] could have an impact on long-term CV risk [36,37]. Recommendations consist of implementing a Mediterranean-type diet, including olive oil and nuts (walnuts, hazelnuts, almonds, $30 \mathrm{~g} /$ day), which currently has the highest level of proof (A1) [38].

\subsection{General nutritional recommendations for $\mathrm{CV}$ prevention}

\subsubsection{Lipid intakes}

Total recommended lipid intake is around $25-35 \%$ of total caloric intake in adults (A2):

- saturated fatty acids (SFA) increase LDLc, and daily intakes should not exceed $8-10 \%$ of energy requirements [39,40]; they should be replaced with oleic acid and polyunsaturated fatty acids (A1) [41];

- trans-unsaturated fatty acids promote an increase of LDLc and decrease of HDLc. Their intake should be as low as possible from processed sources $(<1 \%)$ [42];

- mono-unsaturated fatty acids decrease LDLc as a substitute for SFA. Several studies related to the Mediterranean diet suggest beneficial effects with olive oil consumption for 
preventing $\mathrm{CV}$ events, and an intake of about $15 \%$ of total energy intake (TEI) is recommended (A1) [43];

- polyunsaturated fatty acids lower LDLc and, to a lesser extent, HDLc when they replace SFAs. When used excessively in the form of vegetable oil [omega- 6 fatty acids (FA)], they upset the omega-3/omega-6 FA balance. An increased ratio is recommended at the expense of SFAs, but they should not exceed $10 \%$ of TEI (A2) [44];

Note: There is a very limited level of proof for supplementing with alpha-linolenic acid (ALA) and/or long-chain omega-3 FA (EPA, DHA) above the reference nutrient intake (RNI), according to several recent randomized trials [45]. The WG does not recommend the use of dietary supplements provided that nutritional needs (RNI) are met by a diversified diet, including fish (B1).

- reducing high-cholesterol foods has a variable effect on LDLc that is less than those obtained by adjusting the composition of FA. Moderation to $<300 \mathrm{mg} /$ day is a common-sense measure recommended particularly with mixed intakes rich in SFAs, cholesterol and sodium chloride (such as cold cuts) (B2) [39].

\subsubsection{Fibre intake}

A daily intake of $30-45 \mathrm{~g}$ of fibre, including $5-15 \mathrm{~g} /$ day of soluble fibre, is recommended. Preference should be given to daily consumption of fruit (two portions) and vegetables (three portions) (A2) [46,47]. High intakes of fruit/fruit juices may increase hypertriglyceridaemia.

\subsubsection{Alcohol consumption}

As long as alcohol consumption is low to moderate [0.5-2 U/day ( $1 \mathrm{U}=10 \mathrm{~g}$ pure alcohol)], it is not discouraged as a $\mathrm{CV}$ preventative strategy due to its established association with a moderate reduction of CV risk [48]. This relationship, however, does not demonstrate causation and is independent of the type of alcohol ingested; meta-analyses of observational studies do not show a significant decrease in CV mortality [49].

\subsection{Dietary supplements}

\subsubsection{Phytosterols}

Supplementing with phytosterols remains controversial due to the lack of interventional studies for CV events [50]. At an effective dose ( $2 \mathrm{~g} /$ day), they lower LDLc by $10 \%$ [51]. There is no consensus within the WG on their systematic use in patients with hypercholesterolaemia or a high CV risk (C3) [52,53].

\subsubsection{Red yeast rice (RYR)}

RYR is in fact lovastatin, a first-generation statin, at low doses. The cholesterol lowering effect is not as strong as with statins with marketing authorization (MA), and the production process has not been perfected. Its safety profile is poorly documented. At present, the WG refers to warnings by the ANSM (National Agency for the Safety of Medicines and Health Products) and ANSES (French Agency for Food, Environmental and Occupational Heath and Safety), and does not recommend the use of RYR products in the absence of sufficient quality-control procedures $[54,55]$.

\subsubsection{Policosanol}

This has no conclusive cholesterol lowering effect, according to the latest, strictly controlled studies. Its use is therefore not recommended [56].

\subsection{Influence of lifestyle on TG levels}

It is recommended that there be a focus on weight reduction through physical activity and a balanced low-calorie diet in cases of overweight or obesity. The effects of discontinuing alcohol consumption are yet to be evaluated [57].

The proportion of carbohydrates in relation to TEI is limited to $<50 \%$. Intakes of mono- or disaccharide simple sugars, particularly fructose, is reduced to $<10 \%$ of TEI. In cases of hypertriglyceridaemia, the consumption of sugary drinks is not recommended (sodas, fruit juice), and fruit should be taken in moderation (one per meal). When additional TG-lowering effects are desired through supplementing with omega-3 longchain FA, only high intakes that are considerably greater than the RNI ( $\geq 2 \mathrm{~g} /$ day) have shown any such effects (B2).

Major hypertriglyceridaemia includes the risk of acute pancreatitis, which is considered moderate with TG levels $>10 \mathrm{~g} / \mathrm{L}$ $(11.3 \mathrm{mmol} / \mathrm{L})$ and high with levels $>30 \mathrm{~g} / \mathrm{L}(34 \mathrm{mmol} / \mathrm{L})$. The implementation of strict fasting until TG levels return to the safe range is therefore a nutritional emergency (A3). It is advisable to seek a specialized opinion for possible additional exploratory tests and to choose a subsequently relevant dietary approach: for example, a diet drastically low in fat vs. a balanced low-calorie diet low in simple carbohydrates.

\section{Primary prevention of hypercholesterolaemia and mixed dyslipidaemia}

Risk-calculation tables are inadequate in heterozygous familial hypercholesterolaemia in both children and adults, as they do not incorporate duration of exposure to hypercholesterolaemia and, thus, underestimate the risk, particularly in young adults. There are specific recommendations for the diagnosis and therapeutic indications [8-10]. Screening for dyslipidaemia in first-degree relatives is recommended when LDLc is $>1.9 \mathrm{~g} / \mathrm{L}$ $(4.9 \mathrm{mmol} / \mathrm{L})$ in an index case that establishes the diagnosis of familial hypercholesterolaemia. Clinical and biological predictive scores may support the aetiological diagnosis. It is essential to refer cases of severe heterozygous familial hypercholesterolaemia and children to specialized centres.

\subsection{General treatment recommendations}

Dietary measures are recommended for all patients except those with $\mathrm{LDLc}<1.3 \mathrm{~g} / \mathrm{L}$ and low $\mathrm{CV}$ risk $(\mathrm{SCORE}<1 \%$ ) (A1). In addition to dietary measures and promotion of regular physical activity, smoking cessation support is an important component of the CV prevention process (A1) [2].

For primary prevention in the general population, treatment decisions depend on 10-year CV risk assessment (SCORE calculation or tables, cumulative CVRF) (A2). 
Table 3

Situations with increased risks of muscle-related side-effects (non-exclusive list of indications).

Renal or hepatic failure

History of previous muscle intolerance to lipid-lowering agent

History of myopathy

Preexisting increase of creatine phosphokinase $>3$ times normal

Treatment with drugs that interfere with statin metabolism

(immunosuppressors, antiretrovirals)

Hypothyroidism

Age $>75$ years

Asian origin

Chronic alcohol use

Adapted from Catapano et al. [1], Stone et al. [5] and Hegele et al. [57].

The first-line drug treatment is a statin (A1). For primary prevention, a gradual increase in statin doses is recommended until the target is reached. In cases of intolerance, as confirmed by testing other statins at low doses, or a contraindication to statins, treatment alternatives are ezetimibe or even cholestyramine (B3) [58].

Treatment efficacy and compliance are monitored through lipid testing at 1-3 months and then annually once LDLc is on target and clinical tolerability is satisfactory. During the initial treatment phase, transaminases and blood glucose are measured; creatine phosphokinase (CPK) is checked only in the event of clinical signs or in subjects at risk of muscle complications (Table 3).

\subsection{LDLc objectives and CV risk in primary prevention}

The LDLc concentrations presented in Fig. 1 are thresholds for intervention or intensification, as well as the minimum target to be achieved.
Table 4

Treatment with statins according to their intensity.

\begin{tabular}{lll}
\hline $\begin{array}{l}\text { Low-intensity statin } \\
\text { treatment }\end{array}$ & $\begin{array}{l}\text { Moderate-intensity } \\
\text { statin treatment }\end{array}$ & $\begin{array}{l}\text { High-intensity statin } \\
\text { treatment }\end{array}$ \\
\hline LDLc decrease $<30 \%$ & LDLc decrease $<50 \%$ & LDLc decrease $>50 \%$ \\
\hline Fluvastatin 20-40 mg & Atorvastatin & Atorvastatin \\
Pravastatin 10-20 mg & 10-20 mg & $40-80 \mathrm{mg}$ \\
Simvastatin 10 mg & Fluvastatin 80 mg & Rosuvastatin 20 mg \\
& $\begin{array}{l}\text { Pravastatin 40 mg } \\
\text { Simvastatin 20-40 mg }\end{array}$ \\
& Rosuvastatin 5-10 mg & \\
&
\end{tabular}

Adapted from Stone et al. [5].

LDLc: low-density lipoprotein cholesterol.

\subsubsection{Low CV risk [according to SCORE calculation: risk of $C V$ death at 10 years $<1 \%$ or 0 1 CVRF (excluding diabetes)]}

Statin treatment is overall rarely justified with low $\mathrm{CV}$ risk due to lack of effectiveness. The intervention threshold is $1.9 \mathrm{~g} / \mathrm{L}$ $(4.9 \mathrm{mmol} / \mathrm{L})$, and treatment with a low-intensity statin (Table 4) is generally sufficient (A1).

\subsubsection{Intermediate $C V$ risk (risk of $C V$ death at 10 years between $\geq 1$ and $<5 \%$ or 2 CVRF)}

The threshold is $1.30 \mathrm{~g} / \mathrm{L}(3.4 \mathrm{mmol} / \mathrm{L})$ (B2). This also includes diabetics with no additional risk factors. Statin treatment is usually advisable in this situation.

The HOPE-3 clinical trial explored primary prevention with intermediate risk (CV mortality in the placebo group projected over 10 years: $5.1 \%$ ) and showed the effects of rosuvastatin $10 \mathrm{mg} /$ day on major ischaemic CV events. Mean LDLc at inclusion was $1.27 \mathrm{~g} / \mathrm{L}$, with a mean LDLc decrease of $0.35 \mathrm{~g} / \mathrm{L}$ vs. placebo $[59,60]$.

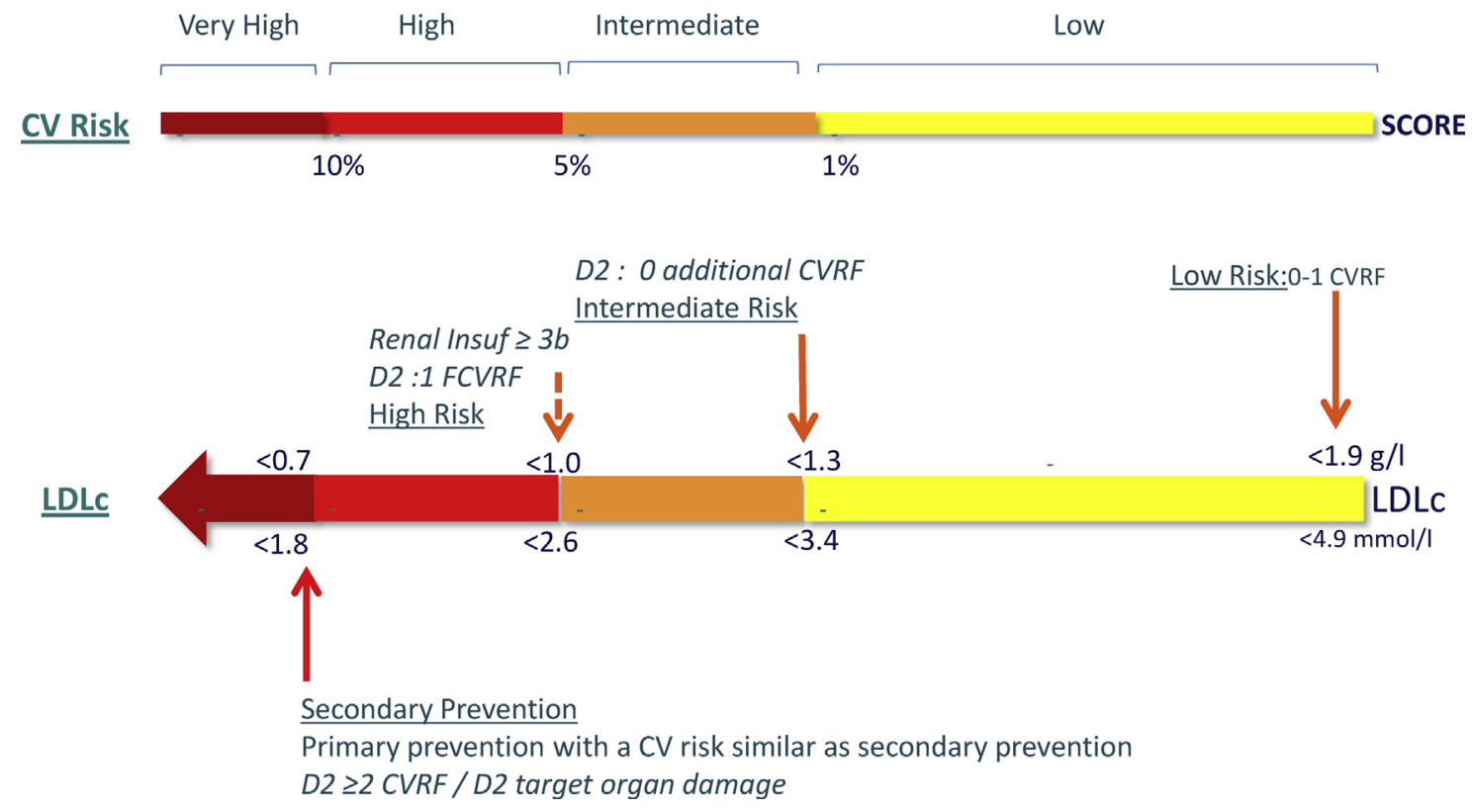

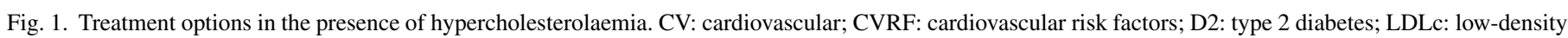
lipoprotein cholesterol. 
This target, however, may be adjusted, and the final decision must take into account the:

- patient's preferences;

- presence of disease associated with increased CV risk, such as chronic inflammatory disease (rheumatoid arthritis), radiation therapy including the heart area, moderate CRF [glomerular filtration rate $(\mathrm{GFR})<60 \mathrm{~mL} / \mathrm{min}$ ] in young subjects;

- presence of subclinical atheroma more serious than expected for age (verified by advanced carotid plaques or a high calcium score), as this reclassifies the subject into the high CV risk category.

\subsubsection{High $C V$ risk (risk of $C V$ death at 10 years $\geq 5 \%$ or $\geq 3 C V R F)$}

The purpose of primary prevention treatment in these patients is to maintain LDLc at $<1 \mathrm{~g} / \mathrm{L}$ (A1). This is the most commonly recommended target for type 2 diabetes, as these patients generally have at least one coexisting CVRF.

Special categories of patients at very high $\mathrm{CV}$ risk may warrant more ambitious targets (LDLc $<0.7 \mathrm{~g} / \mathrm{L}$ ). This small, select group includes patients presenting with diabetes and target-organ involvement (confirmed nephropathy, stage 2+ retinopathy: moderate preproliferative) or with $>2$ CVRF in addition to diabetes (A2). In cases of haemodialysis or renal transplantation, there are no longer any indications for introducing a statin at this stage (B2); however, statins that were started previously during the severe CRF stage need not be discontinued (C2).

\subsection{Special cases of mixed dyslipidaemia}

The most recent epidemiological data suggest that hypertriglyceridaemia has independent proatherogenic effects even in the absence of diabetes or the metabolic syndrome (MetS) [61-63]. However, the atherogenicity of hypertriglyceridaemia is less intense overall than that of hypercholesterolaemia, and LDLc remains the priority target in terms of $\mathrm{CV}$ prevention (Fig. 2). As a result, the presence of mixed hyperlipidaemia with moderate hypertriglyceridaemia $(<5 \mathrm{~g} / \mathrm{L})$ does not change the therapeutic management for isolated hypercholesterolaemia $[64,65]$. The dietary and lifestyle guidelines concerning hypertriglyceridaemia are given together with those of hypercholesterolaemia, as they play particularly important roles in controlling hypertriglyceridaemia (A1). The process of using cholesterol lowering agents is the same for high or very high risk in primary prevention (B3).

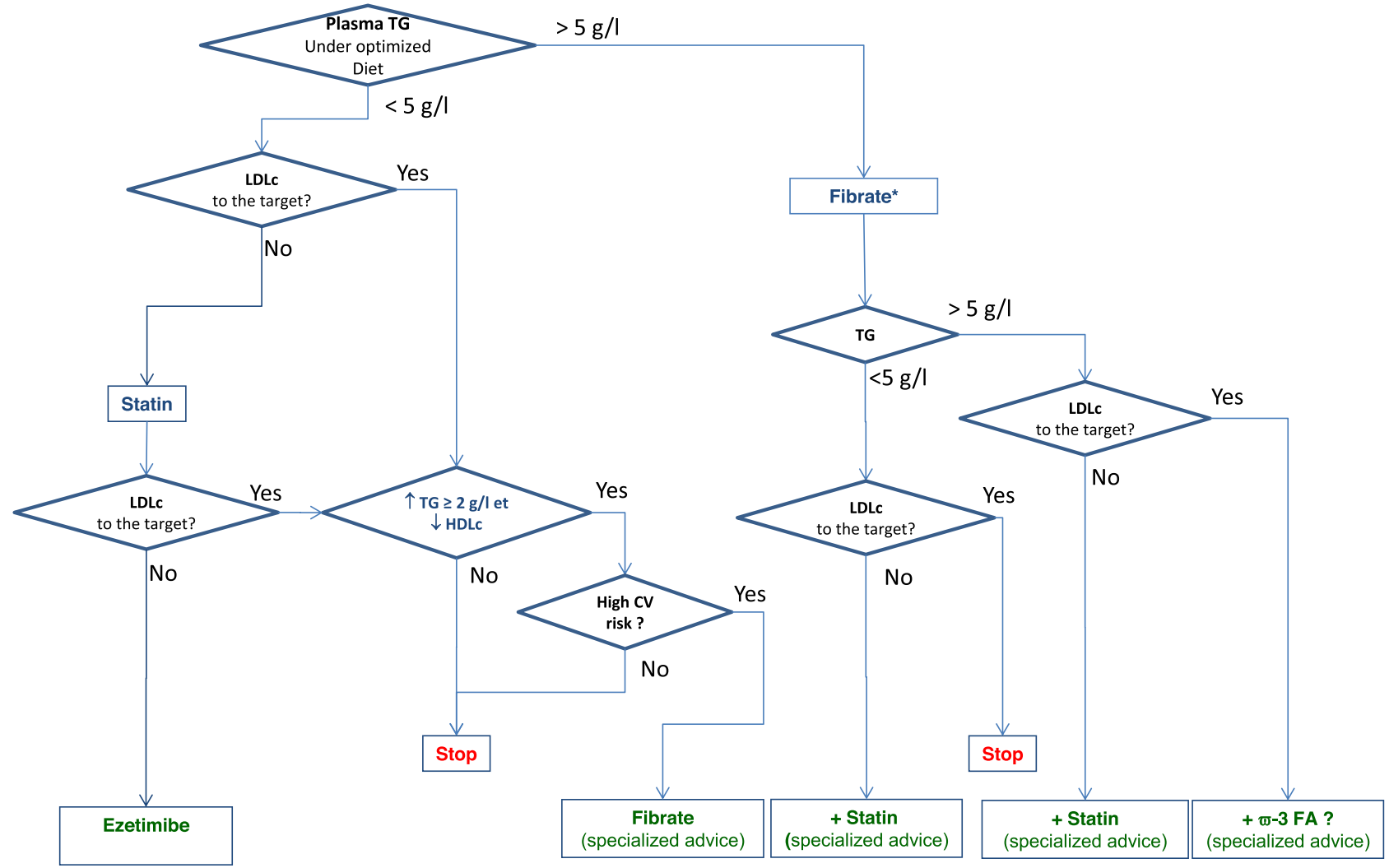

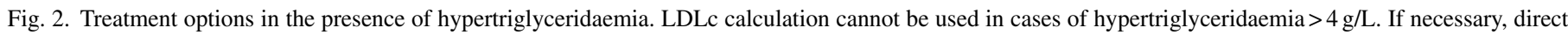

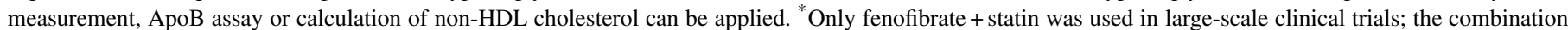

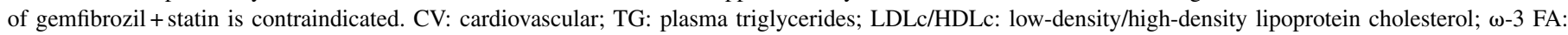
omega-3 fatty acids. 
4.3.1. Mixed dyslipidaemia including moderate hypertriglyceridaemia [<5 g/L $(5.6 \mathrm{mmol} / \mathrm{L})]$

4.3.1.1. LDLc is on target using dietary/lifestyle measures and/or statins. With moderate hypertriglyceridaemia $(2-5 \mathrm{~g} / \mathrm{L})$, fibrates are an option only if two other conditions are also met (B3) [66-69]: low HDLc ( $\leq 0.4 \mathrm{~g} / \mathrm{L})$; and high or very high CV risk.

Specialist advice is recommended for a statin/fibrate combination (B2) [70]. Due to its risk of drug interactions, gemfibrozil is contraindicated in combination with statins and, therefore, fenofibrate should be used (B3).

4.3.1.2. LDLc is not on target despite dietary/lifestyle measures and/or statins. The priority is to reach the LDLc target by using and titrating a statin (A1). If the statin is at the optimal dose and dietary/lifestyle measures have been used, yet LDLc is still not on target, then ezetimibe should be added to the statin (B2) [71].

\subsubsection{Mixed dyslipidaemia including high}

hypertriglyceridaemia $(>5 \mathrm{~g} / \mathrm{L})$

Use of a first-line fibrate is mainly for hypertriglyceridaemia $\geq 5 \mathrm{~g} / \mathrm{L}$ and resistant to dietary/lifestyle measures, with the aim of reducing the risk of acute pancreatitis via a decrease in TG levels (B3). However, there are no controlled clinical trials to validate this hypothesis [72]. Specialist advice is necessary in cases of treatment-resistant hypertriglyceridaemia or severe hypercholesterolaemia.

\section{Management of hypercholesterolaemia and mixed dyslipidaemia for secondary prevention of ischaemic CV complications}

Only one randomized, open-label, study has been done using dosage titration for achieving an LDLc target $<0.8 \mathrm{~g} / \mathrm{L}$ [73]. During this trial of patients with stable coronary insufficiency, mean LDLc decreased to $0.95 \mathrm{~g} / \mathrm{L}$ in the intervention group vs. $1.10 \mathrm{~g} / \mathrm{L}$. Benefit was seen for the composite primary endpoint and non-fatal infarction.

Baseline plasma concentrations of LDLc and those obtained with treatment during clinical trials also provide objective reference points for directing treatments. In meta-regression interventional studies, a linear relationship is retained between the magnitude of LDLc decrease and reduction of relative risk (RR) of major ischaemic events, and the gain in RR persists in subgroup analyses of LDLc levels close to $0.7 \mathrm{~g} / \mathrm{L}$, but with a simultaneous increase in the number of people to be treated [74].

It is recommended that a high-intensity statin be used from the outset for secondary prevention (atorvastatin $80 \mathrm{mg}$ ), except in cases of LDLc that is not high at baseline and/or with a significant risk of muscle side effects (Table 3 ). The increased risk of type 2 diabetes is largely offset by the reduced risk of recurrent ischaemic complications.

An LDLc target $<0.70 \mathrm{~g} / \mathrm{L}(1.8 \mathrm{mmol} / \mathrm{L})$ is recommended (A2). This threshold is based on:
- results of randomized controlled trials (RCTs) testing treatment strategies using high-intensity vs. lower-intensity statin treatments [75-79];

- results of IMPROVE-IT (Improved Reduction of Outcomes: Vytorin Efficacy International Trial) [80];

- consideration of extrapolations from meta-analyses and analyses of extreme subgroups [74,81-83].

If the LDLc target is not reached by monotherapy using the maximum tolerated statin dose, the addition of ezetimibe should be considered (A2). During IMPROVE-IT, intensification of the cholesterol lowering treatment decreased LDLc from $0.7 \mathrm{~g} / \mathrm{L}$ to $0.54 \mathrm{~g} / \mathrm{L}$, with a significant $2 \%$ reduction in absolute value of the primary endpoint. This enabled one major ischaemic event to be avoided through the annual treatment of 300 people [80]. Other studies are now being conducted to explore lower LDLc targets, with some proposing a target of $0.5 \mathrm{~g} / \mathrm{L}(1.3 \mathrm{mmol} / \mathrm{L})$. The effectiveness (cost/efficacy ratio) of such objectives needs to be evaluated.

When the maximum treatment dose fails to decrease LDLc to $<0.7 \mathrm{~g} / \mathrm{L}$, a $50 \%$ reduction of LDLc is considered an acceptable compromise $[1,5]$. Nevertheless, a patient who maintains a high LDLc despite such a reduction continues to have a high residual $\mathrm{CV}$ risk.

In the event of adverse reactions with a high-dose statin or statin-ezetimibe combination, the use of a low- to moderatedose statin with an LDLc target $<1 \mathrm{~g} / \mathrm{L}$ is recommended (C1). In the event of statin intolerance, monotherapy with ezetimibe or even cholestyramine should be used (C2).

In cases of associated hypertriglyceridaemia, the strategy considered for mixed dyslipidaemia (see Section 4.3.1 above) should be used.

If LDLc remains $>2 \mathrm{~g} / \mathrm{L}$ in secondary prevention with the maximum tolerated treatment, the patient should be referred to a specialized centre for consideration of LDL apheresis (A3).

\section{Other special situations}

\subsection{Management of isolated hypertriglyceridaemia}

People with a history of major hypertriglyceridaemia ( $>10 \mathrm{~g} / \mathrm{L}$ ) require a specialist's opinion (Fig. 2). Dietary and physical activity measures play a central role in controlling isolated hypertriglyceridaemia (A1). Secondary factors, such as diabetes and MetS, are particularly common with hypertriglyceridaemia and need to be addressed.

\subsubsection{Persistent hypertriglyceridaemia $\geq 5 \mathrm{~g} / \mathrm{L}$ despite dietary/lifestyle measures}

A fibrate should be used as the first-line monotherapy (A1). In cases of persistent hypertriglyceridaemia $\geq 5 \mathrm{~g} / \mathrm{L}$ despite dietary/lifestyle measures and fibrate therapy at optimal doses, high-dose omega-3 long-chain FA ( $>2$ g/day of EPA/DHA) may be added after specialist consultation (C3). While these products are no longer reimbursed in France as medications, they are available as dietary supplements. If hypertriglyceridaemia persists at $\geq 5 \mathrm{~g} / \mathrm{L}$ despite dietary/lifestyle measures and fibrate 
therapy at optimal doses, and LDLc levels are not on target despite the patient's RR (measured by a direct method or by non-HDLc determination), a statin could be added to fenofibrate following specialist consultation (C3).

\subsubsection{Moderate isolated hypertriglyceridaemia $(2-5 \mathrm{~g} / \mathrm{L})$ despite dietary/lifestyle measures \\ $\mathrm{CV}$ risk estimates take precedence:}

- if the risk is low to intermediate, there is no need to add a fibrate;

- if it is high with LDLc on target, the use of a fibrate should be considered, as per the Veterans Affairs High-Density Lipoprotein Cholesterol Intervention Trial (VA-HIT) and Helsinki Heart Study (HHS) [84,85].

\section{2. $H D L c \leq 0.30 \mathrm{~g} / \mathrm{L}$ with no secondary factors}

It is important to seek a specialist's opinion for establishing the aetiological diagnosis and evaluating the opportunity for treatment. The decision is based on investigation of subclinical atheroma. If there is reclassification to a high $\mathrm{CV}$ risk, a statin should be proposed, although the level of proof is limited due to the lack of specific clinical trials of this setting (B3).

\subsection{Elderly people ( $>75$ years)}

When epidemiological studies are carried out with adjustment of health status indicators (albumin, iron, etc.), a positive relationship between LDLc and CV risk is found even in elderly populations [86-89]. Meta-analyses and the PROSPER study have shown CV benefit from statins in the elderly [90-92], and several cohort studies have found no increased risk of cancer or cognitive impairment.

Identification of hypercholesterolaemia in elderly subjects with no CV history should prompt investigations for possible secondary dyslipidaemia (C3).

In the elderly, initiation or continuation of treatment with a statin needs to be considered on the basis of comorbidities and the potential benefit that the treatment may provide (C2).

It is advisable to continue statin treatment after the age of 75 years in subjects who are already being treated and tolerate the treatment (B1) [5].

For primary prevention, if associated $\mathrm{CV}$ risk factors and advanced non-complicated atheroma are present, the use of low-dose statin treatment in those aged $75-80$ years should be carefully weighed. The decision should take into account the absence of severe comorbidities; secondary hyperlipidaemia should also be ruled out and a low dose selected (B2) [1,5].

For secondary prevention, it is advisable to treat elderly subjects with a statin for an LDLc target value $<1.0 \mathrm{~g} / \mathrm{L}$ (B2).

\section{Conclusion}

This consensus statement is based on information that has heterogeneous levels of proof and is supported by analyses of the continually evolving literature. Genetic dyslipidaemia has specific recommendations, as estimates of risk and treatment implications differ. There are specific consensuses for these situations. The present synthesized recommendation addresses the general population of subjects with dyslipidaemia and CV risk. Given the prevalence of diabetes and renal failure and their attendant $\mathrm{CV}$ risks, and the secondary dyslipidaemia observed in these situations, some reference markers have been provided for these populations, including specific recommendations for their management. Following the emergence of generic statins, and the subsequent period of cost reductions, for the treatment of dyslipidaemia, the development of new, more expensive, drugs will soon require reevaluation of certain indications with the aim of providing optimal management and treatment based on efficacy as well as cost.

\section{Document review group}

F. Boccara, Paris, NSFA; M. Farnier, Dijon, NSFA; B. Feve, Paris, SFE; P. Gourdy, Toulouse, SFE; B. Guerci, Nancy, SFD; M. Krempf, Nantes, SFD.

\section{Disclosure of interest}

The participants declare having scientific activities involving earnings or research funding (conferences, clinical trials or research grants) during the years 2012-2016.

\section{Working group}

S Béliard: Aegerion Pharmaceuticals, Amgen, Isis (now Ionis) Pharmaceuticals, MSD, Novartis, Novo Nordisk, Sanofi.

F. Bonnet: Amgen, AstraZeneca/Bristol-Myers Squibb, Boehringer Ingelheim, Coca-Cola, ISA, Eli Lilly, MSD, Novo Nordisk, Sanofi, Takeda Pharmaceutical.

B. Bouhanick: AstraZeneca, Eli Lilly, Novo Nordisk, Sanofi.

E. Bruckert: Aegerion Pharmaceuticals, Amgen, Chiesi, Danone, Genfit, Ionis Pharmaceuticals, MSD, Eli Lilly, Regeneron, Rottapharm MEDA, Sanofi, Unilever.

B. Cariou: Amgen, AstraZeneca, Genfit, Janssen Pharmaceutical, Eli Lilly, Novartis, MSD, Novo Nordisk, Laboratoires Pierre Fabre, Regeneron, Sanofi, Takeda Pharmaceutical.

S. Charriere: AstraZeneca, Boehringer Ingelheim, Eli Lilly, Merck Serono, MSD, Novartis, Novo Nordisk, Sanofi.

V. Durlach: AstraZeneca, Amgen, Bioprojet Pharma, Sanofi.

P. Moulin: Aegerion Pharmaceuticals, Akcea Therapeutics/Ionis Pharmaceuticals, Amgen, AMT, AstraZeneca/BristolMyers Squibb, Chiesi, Unicure Pharmaceutical, Janssen Pharmaceutical, Eli Lilly, MSD, Novartis, Novo Nordisk, Olympus, Laboratoires Pierre Fabre, Regeneron, Sanofi, Servier.

R. Valéro: Amgen, AstraZeneca, Chiesi, Danone, Isis (now Ionis) Pharmaceuticals, Janssen Pharmaceutical, Lesieur, Eli Lilly, MSD, Novo Nordisk, Sanofi, Unilever.

B. Vergès: AstraZeneca/Bristol-Myers Squibb, Bayer Pharma, Janssen Pharmaceutical, MSD, Novartis Pharma, Novo Nordisk, Novartis, Sanofi, Servier, Takeda Pharmaceutical. 


\section{Document review group}

F. Boccara: Amgen, Bristol-Myers Squibb, Janssen Pharmaceutical, MSD, Regeneron, Sanofi, Gilead, ViiV Healthcare.

M. Farnier: Mylan/Abbott Laboratories, Akcea Therapeutics/Ionis Pharmaceuticals, Amgen, AstraZeneca, Eli Lilly, Kowa American Corporation, Merck \& Co, Pfizer, Roche Diagnostics, Sanofi/Regeneron, Servier.

B. Feve: AstraZeneca/Bristol-Myers Squibb, Sanofi Aventis, GlaxoSmithKline, Novartis, Novo Nordisk, Janssen Pharmaceutical, MSD, Eli Lilly, Boehringer Ingelheim, Intarcia Therapeutics, MetaCure, Pfizer, MSD, Roche Diagnostics, Medtronic, A. Menarini Diagnostics, Abbott Laboratories, Vita1Aire, Dinno Santé, Orkyn, ViiV Healthcare.

P. Gourdy: AstraZeneca/Bristol-Myers Squibb, Boehringer Ingelheim, Janssen Pharmaceutical, Eli Lilly, GSK, MSD, Novartis, Novo Nordisk, Laboratoires Pierre Fabre, Sanofi, Servier, Takeda Pharmaceutical.

B. Guerci: Abbott Laboratories, AstraZeneca/Bristol-Myers Squibb, Boehringer Ingelheim, Dinno Santé, Eli Lilly, Intarcia Therapeutics, Janssen Pharmaceutical, GSK, Medtronic, A. Menarini Diagnostics, MetaCure, MSD, Novartis, Novo Nordisk, Orkyn, Pfizer, Roche Diagnostics, Sanofi Aventis, Vita1Aire.

M. Krempf: AstraZeneca, Amgen, Boehringer Ingelheim, Danone, Eli Lilly, Ionis Pharmaceuticals, Janssen Pharmaceutical, A. Menarini Diagnostics, MSD, Novartis, Novo Nordisk, Sanofi, Unilever.

\section{Acknowledgements}

The logistics related to setting up these guidelines were supported by an unrestricted grant from the French Society of Endocrinology.

\section{References}

[1] Catapano AL, Reiner Z, De Backer G, Graham I, Taskinen MR, Wiklund $\mathrm{O}$, et al. ESC/EAS guidelines for the management of dyslipidemias the task force for the management of dyslipidemias of the European Society of Cardiology (ESC) and the European Atherosclerosis Society (EAS). Atherosclerosis 2011;217:3-46.

[2] Perk J, De Backer G, Gohlke H, Graham I, Reiner Z, Verschuren WM, et al. European guidelines on cardiovascular disease prevention in clinical: the fifth joint task force of the European Society of Cardiology and Other Societies on Cardiovascular Disease prevention in clinical practice (constituted by representatives of nine societies and by invited experts). Atherosclerosis 2012;223:1-68.

[3] Expert Panel on Dyslipidemia. An International Atherosclerosis Society Position Paper: global recommendations for the management of dyslipidemia. Executive Summary. Atherosclerosis 2014;232:410-3.

[4] Piepoli MF, Hoes AW, Agewall S, Albus C, Brotons C, Catapano AL, et al. Authors/Task Force Members. 2016 European Guidelines on cardiovascular disease prevention in clinical practice: The Sixth Joint Task Force of the European Society of Cardiology and Other Societies on Cardiovascular Disease Prevention in Clinical Practice (constituted by representatives of 10 societies and by invited experts): developed with the special contribution of the European Association for Cardiovascular Prevention \& Rehabilitation (EACPR). Eur Heart J 2016 (in press, pii:ehw106).

[5] Stone NJ, Robinson JG, Lichtenstein AH, Bairey Merz CN, Blum CB, Eckel RH, et al. 2013 ACC/AHA guideline on the treatment of blood cholesterol to reduce atherosclerotic cardiovascular risk in adults: a report of the American College of Cardiology/American Heart Association Task Force on practice guidelines. Circulation 2014;129(25 Suppl. 2): S49-73.

[6] Lloyd-Jones DM, Morris PB, Ballantyne CM, Birtcher KK, Daly Jr DD, DePalma SM, et al. ACC expert consensus decision pathway on the role of non-statin therapies for LDL-cholesterol lowering in the management of atherosclerotic cardiovascular disease risk. J Am Coll Cardiol 2016, http://dx.doi.org/10.1016/j.jacc.2016.03.519 [in press].

[7] Guideline Development Group. Lipid modification and cardiovascular risk assessment for the primary and secondary prevention of cardiovascular disease: summary of updated NICE guidance. BMJ 2014;349: 4356.

[8] Farnier M, Bruckert E, Boileau C, Krempf M. Nouvelle Société française d'athérosclérose. Diagnostic and treatment of familial hypercholesterolemia $(\mathrm{FH})$ in adults: guidelines from the New French Society of Atherosclerosis (NSFA). Presse Med 2013;42:930-50.

[9] Nordestgaard BG, Chapman MJ, Humphries SE, Ginsberg HN, Masana L, Descamps OS, et al. European Atherosclerosis Society Consensus Panel. Familial hypercholesterolemia is underdiagnosed and undertreated in the general population: guidance for clinicians to prevent coronary heart disease: consensus statement of the European Atherosclerosis Society. Eur Heart J 2013;34:3478-90.

[10] Wiegman A, Gidding SS, Watts GF, Chapman MJ, Ginsberg HN, Cuchel M, et al. European Atherosclerosis Society Consensus Panel. Eur Heart J 2015;36:2425-37.

[11] ADA Position statement cardiovascular disease and risk management. Diabetes Care 2015;38(Suppl. 1):S49-57.

[12] Ryden L, Grant PJ, Anker SD, Berne C, Cosentino F, Danchin N, et al. ESC Guidelines on diabetes, pre-diabetes, and cardiovascular diseases developed in collaboration with the EASD. Eur Heart J 2013;34:3035-87.

[13] https://www.steno.shinyapps.io/T1RiskEngine/ (diabète de type 1).

[14] http://www.advanceriskengine.com/ (diabète de type 2).

[15] https://www.dtu.ox.ac.uk/riskengine/ (diabète de type 2).

[16] www.escardio.org/static_file/Escardio/Subspecialty/EACPR/Documents/ score-charts.pdf.

[17] Nordestgaard BG, Langsted A, Mora S, Kolovou G, Baum H, Bruckert E, et al. European Atherosclerosis Society (EAS) and the European Federation of Clinical Chemistry and Laboratory Medicine (EFLM) joint consensus initiative. Fasting is not routinely required for determination of a lipid profile: clinical and laboratory implications including flagging at desirable concentration cut-points - a joint consensus statement from the European Atherosclerosis Society and European Federation of Clinical Chemistry and Laboratory Medicine. Eur Heart J 2016 [in press. pii:ehw152].

[18] Brewer Jr HB. Clinical review: the evolving role of HDL in the treatment of high risk patients with cardiovascular disease. J Clin Endocrinol Metab 2011;96:1246-57.

[19] Ramjee V, Sperling LS, Jacobson TA. Non-high-density lipoprotein cholesterol versus apolipoprotein B in cardiovascular risk stratification: do the math. J Am Coll Cardiol 2011;58:457-63.

[20] Nordestgaard BG, for the European Atherosclerosis Society Consensus Panel. Lipoprotein(a) as a cardiovascular risk factor: current status. Eur Heart J 2010;31:2844-53.

[21] Shah T, Casas JP, Cooper JA, Tzoulaki I, Sofat R, McCormack V, et al. Critical appraisal of CRP measurement for the prediction of coronary heart disease events: new data and systematic review of 31 prospective cohorts. Int J Epidemiol 2009;38:217-31.

[22] Thompson A, Gao P, Orfei L, Watson S, Di Angelantonio E, Kaptoge S, et al. Lipoprotein-associated phospholipase A(2) and risk of coronary disease, stroke, and mortality: collaborative analysis of 32 prospective studies. Lancet 2010;375:1536-44.

[23] Paynter NP, Chasman DI, Paré G, Buring JE, Cook NR, Miletich JP, et al. Association between a literature-based genetic risk score and cardiovascular events in women. JAMA 2010;303:631-7.

[24] Tada H, Melander O, Louie JZ, Tanese JJ, Rowland CM, Devlin JJ, et al. Risk prediction by genetic risk scores for coronary heart disease is independent of self-reported family history. Eur Heart J 2016;37: $561-7$. 
[25] Greenland P, Alpert JS, Beller GA, Benjamin EJ, Budoff MJ, Fayad ZA, et al. American Heart Association. 2010 ACCF/AHA guideline for assessment of cardiovascular risk in asymptomatic adults: a report of the American College of Cardiology foundation/American Heart Association Task Force on Practice Guidelines. J Am Coll Cardiol 2010;56:e50-103.

[26] Mancia G, Fagard R, Narkiewicz K, Redon J, Zanchetti A, Böhm M, et al. ESH/ESC guidelines for the management of hypertension. J Hypertens 2013:31:1281-357.

[27] Kavousi M, Elias-Smale S, Rutten JH, Leening MJ, Vliegenthart R, Verwoert GC, et al. Evaluation of newer risk markers for coronary heart disease risk classification: a cohort study. Ann Intern Med 2012:156:438-44.

[28] Yeboah J, Young R, McClelland RL, Delaney JC, Polonsky TS, Dawood FZ, et al. Utility of non-traditional risk markers in atherosclerotic cardiovascular disease risk assessment. J Am Coll Cardiol 2016;67:139-47.

[29] deGoma EM, Dunbar RL, Jacoby D, French B. Differences in absolute risk ofcardiovascular events using risk-refinement tests: a systematic analysis of four cardiovascular risk equations. Atherosclerosis 2013;227: $172-7$.

[30] Inaba Y, Chen JA, Bergmann SR. Carotid plaque, compared with carotid intima media thickness, more accurately predicts coronary artery disease events: a meta-analysis. Atherosclerosis 2012;220:128-33.

[31] Brott TG, Halperin JL, Abbara S, Bacharach JM, Barr JD, Bush RL, et al. ASA/ACCF/AHA/AANN/AANS/ACR/ASNR/CNS/SAIP/SCAI/SIR/ SNIS/SVM/SVS guideline on the management of patients with extracranial carotid and vertebral artery disease: executive summary. Circulation 2011:124:489-532.

[32] https://www.mesa-nhlbi.org/Calcium/input.aspx.

[33] Roberts ET, Horne A, Martin SS, et al. Cost-effectiveness of coronary artery calcium testing for coronary heart and cardiovascular disease risk prediction to guide statin allocation: the Multi-Ethnic Study of Atherosclerosis (MESA). PLoS One 2015;10:e0116377.

[34] Montalescot G, Sechtem U, Achenbach S, et al. 2013 ESC guidelines on the management of stable coronary artery disease: the Task Force on the management of stable coronary artery disease of the European Society of Cardiology. Eur Heart J 2013;34:2949-3003.

[35] Mente A, de Koning L, Shannon HS, Anand SS. A systematic review of the evidence supporting a causal link between dietary factors and coronary heart disease. Arch Intern Med 2009;169:659-69.

[36] Hu F, Willett WC. Optimal diets for prevention of coronary heart disease. JAMA 2002;288:2569-78.

[37] Spring B, Moller AC, Colangelo LA, Siddique J, Roehrig M, Daviglus ML, et al. Healthy lifestyle change and subclinical atherosclerosis in young adults: Coronary Artery Risk Development in Young Adults (CARDIA) study. Circulation 2014;130:10-7.

[38] Estruch R, Ros E, Salas-Salvadó J, Covas MI, Corella D, Arós F, et al. Primary prevention of cardiovascular disease with a Mediterranean diet. N Engl J Med 2013;168:1279-990.

[39] Astrup A, Dyerberg J, Elwood P, Hermansen K, Hu FB, Jakobsen MU, et al. The role of reducing intakes of saturated fat in the prevention of cardiovascular disease: where does the evidence stand in 2010? Am J Clin Nutr 2011;93:684-8.

[40] Siri Tarino PW, Sun Q, Hu FB, Krauss RM. Meta-analysis of prospective cohort studies evaluating the association of saturated fat with cardiovascular disease. Am J Clin Nutr 2010;91:535-46.

[41] Al-Khudairy L, Hartley L, Clar C, Flowers N, Hooper L, Rees K. Omega-6 fatty acids for the primary prevention of cardiovascular disease. Cochrane Database Syst Rev 2015;11:CD011094.

[42] Mozaffarian D, Katan MB, Ascherio A, Stampfer MJ, Willett WC. Trans fatty acids and cardiovascular disease. N Engl J Med 2006;354:1601-13.

[43] http://www.health.gov/dietaryguidelines/2015-scientific-report/.

[44] Harris WS, Mozaffarian D, Rimm E, Kris-Etherton P, Rudel LL, Appel LJ, et al. Omega-6 fatty acids and risk for cardiovascular disease: a science advisory from the American Heart Association Nutrition Subcommittee of the Council on Nutrition, Physical Activity, and Metabolism; Council on Cardiovascular Nursing; and Council on Epidemiology and Prevention. Circulation 2009;119:902-7.

[45] Rizos EC, Ntzani EE, Bika E, Kostapanos MS, Elisaf MS. Association between $\omega-3$ fatty acid supplementation and risk of major cardiovascular disease events: a systematic review and meta-analysis. JAMA 2012;308:1024-33.

[46] Hartley L, May MD, Loveman E, Colquitt JL, Rees K. Dietary fibre for the primary prevention of cardiovascular disease. Cochrane Database Syst Rev 2016;1:CD011472

[47] Dauchet L, Amouyel P, Hercberg S, Dallongeville J. Fruit and vegetable consumption and risk of coronary heart disease: a meta-analysis of cohort studies. J Nutr 2006;136:2588-93.

[48] Rimm EB, Williams P, Fosher K, Criqui M, Stampfer MJ. Moderate alcohol intake and lower risk of coronary heart disease: meta-analysis of effects on lipids and haemostatic factors. BMJ 1999;319:1523152-8.

[49] Zheng YL, Lian F, Shi Q, Zhang C, Chen YW, Zhou YH, et al. Alcohol intake and associated risk of major cardiovascular outcomes in women compared with men: a systematic review and meta-analysis of prospective observational studies. BMC Public Health 2015;15:773-9.

[50] De Jong A, Plat J, Bast A, Godschalk RW, Basu S, Mensink RP. Effects of plant sterol and stanol ester consumption on lipid metabolism, antioxidant status and markers of oxidative stress, endothelial function and low-grade inflammation in patients on current statin treatment. Eur J Clin Nutr 2008;62:263-73.

[51] Bard JM, Paillard F, Lecerf JM. Effect of phytosterols/stanols on LDL concentration and other surrogate markers of cardiovascular risk. Diabetes Metab 2015;41:69-75.

[52] Vergès B, Fumeron F. Potential risks associated with increased plasma plant sterol levels. Diabetes Metab 2015;41:76-81.

[53] www.anses.fr/fr/system/files/NUT2010sa0057Ra.pdf.

[54] https://www.anses.fr/fr/content/compl\%C3\%A9ments-alimentaires-\%C3 $\%$ A0-base-de-levure-de-riz-rouge-avant-consommation-prenez-conseil.

[55] http://www.ansm.sante.fr/S-informer/Points-d-information-Points-dinformation/Complements-alimentaires-a-base-de-levure-de-riz-rougemises-en-garde-de-1-ANSM-Point-d'information/\%28language\%29/ fre-FR.

[56] Berthold HK, Unverdorben S, Degenhardt R, Bulitta M, Gouni-Berthold I. Effect of policosanol on lipid levels among patients with hypercholesterolemia or combined hyperlipidemia: a randomized controlled trial JAMA 2006;295:2262-9.

[57] Hegele RA, Ginsberg HN, Chapman MJ, Nordestgaard BG, Kuivenhoven JA, Averna M, et al. European Atherosclerosis Society Consensus Panel. The polygenic nature of hypertriglyceridemia: implications for definition, diagnosis, and management. Lancet Diabetes Endocrinol 2014;2: $655-66$.

[58] Stroes ES, Thompson PD, Corsini A, Vladutiu GD, Raal FJ, Ray KK, et al European Atherosclerosis Society Consensus Panel. Statin-associated muscle symptoms:impact on statin therapy-European Atherosclerosis Society Consensus Panel Statement on Assessment, Aetiology and Management. Eur Heart J 2015;36:1012-22.

[59] Yusuf S, Bosch J, Dagenais G, Zhu J, Xavier D, Liu L, et al. Cholesterol lowering in intermediate-risk persons without cardiovascular disease. N Engl J Med 2016 [Epub ahead of print. PubMed PMID: 27040132].

[60] Yusuf S, Lonn E, Pais P, Bosch J, López-Jaramillo P, Zhu J, et al. Blood-pressure and cholesterol lowering in persons without cardiovascular disease. N Engl J Med 2016.

[61] Hokanson JE, Austin MA. Plasma triglyceride level is a risk factor for cardiovascular disease independent of high- density lipoprotein cholesterol level: a meta-analysis of population-based prospective studies. J Cardiovasc Risk 1996;3:213-9.

[62] Sarwar N, Danesh J, Eiriksdottir G, Sigurdsson G, Wareham N, Bingham S, et al. Triglycerides and the risk of coronary heart disease: 10,158 incident cases among 262,525 participants in 29 Western prospective studies. Circulation 2007;115:450-8

[63] Tirosh A, Rudich A, Shochat T, Tekes-Manova D, Israeli E, Henkin Y, et al Changes in triglyceride levels and risk for coronary heart disease in young men. Ann Intern Med 2007;147:377-85.

[64] Chapman MJ, Ginsberg HN, Amarenco P, Andreotti F, Borén J, Catapano AL, et al. 2013 ACC/AHA guideline on the assessment. Triglyceride-rich lipoproteins and high-density lipoprotein cholesterol in patients at high risk of cardiovascular risk: a report disease: evidence and guidance for management. Eur Heart J 2011;32:1345-61. 
[65] Miller M, Stone NJ, Ballantyne C, Bittner V, Criqui MH, Ginsberg HN, et al. Triglycerides and cardiovascular disease: a scientific statement from the American Heart Association. Circulation 2011;123:2292-333.

[66] Berglund L, Brunzel JD, Goldberg AV, Goldberg IJ, Sacks F, Murad $\mathrm{MH}$, et al. Evaluation and treatment of hypertriglyceridemia: an endocrine society clinical practice guideline. J Clin Endocrinol Metab 2012;97: 2969-89.

[67] Reiner Z, Catapano AL, De Backer G, Graham I, Taskinen MR, Wiklund O, et al. ESC/EAS Guidelines for the management of dyslipidemias: the American CollegeTask Force for the management of dyslipidemias of the European Society of Cardiology/American Heart Association Task Force on Practice Guidelines. Circulation 2014;129:S49-73. (ESC) and the European Atherosclerosis Society (EAS). Eur Heart J 2011;32: $1769-818$

[68] Rabar S, Harker M, O’Flynn N, Wierzbicki AS, Guideline Development Group. Lipid modification and cardiovascular risk assessment for the primary and secondary prevention of cardiovascular disease: summary of updated NICE guidance. BMJ 2014;349:g4356.

[69] The FIELD study investigators. Effects of long-term fenofibrate therapy on cardiovascular events in 9795 people with type 2 diabetes mellitus (the FIELD study): randomised controlled trial. Lancet 2005;366:1849-61.

[70] Sacks FM, Carey VJ, Fruchart JC. Combination lipid therapy in type 2 diabetes. N Engl J Med 2010;363:692-4.

[71] Ginsberg HN, Elam MB, Lovato LC, Crouse 3rd JR, Leiter LA, Linz P, et al. Effects of combination lipid therapy in type 2 diabetes mellitus. $\mathrm{N}$ Engl J Med 2010;362:1563-74.

[72] Berglund L, Brunzell JD, Goldberg AC, Goldberg IJ, Stalenhoef A. Treatment options for hypertriglyceridemia: from risk reduction to pancreatitis. Best Pract Res Clin Endocrinol Metab 2014;28:423-37.

[73] Koren MJ, Hunninghake DB, Investigators ALLIANCE. Clinical outcomes in managed-care patients with coronary heart disease treated aggressively in lipid-lowering disease management clinics: the alliance study. J Am Coll Cardiol 2004;44:1772-9

[74] Cholesterol Treatment Trialists' (CTT) Collaboration, Baigent C, Blackwell L, Emberson J, Holland LE, Reith C, et al. Efficacy and safety of more intensive lowering of LDL-cholesterol: a meta-analysis of data from 170,000 participants in 26 randomised trials. Lancet 2010;376:1670-81.

[75] Armitage J, Bowman L, Wallendszus K, Armitage J, Bowman L, Wallendszus K, et al. Study of the Effectiveness of Additional Reductions in Cholesterol and Homocysteine (SEARCH) Intensive lowering of LDL-cholesterol with $80 \mathrm{mg}$ versus $20 \mathrm{mg}$ simvastatin daily in 12,064 survivors of myocardial infarction: a double-blind randomised trial. Lancet 2010;376:1658-69.

[76] De Lemos JA, Blazing MA, Wiviott SD, Lewis EF, Fox KA, White HD, et al. Early intensive vs a delayed conservative simvastatin strategy in patients with acute coronary syndromes: phase $\mathrm{Z}$ of the $\mathrm{A}$ to $\mathrm{Z}$ trial. JAMA 2004;292:1307-16.

[77] LaRosa JC, Grundy SM, Waters DD, Shear C, Barter P, Fruchart JC, et al. Intensive lipid lowering with atorvastatin in patients with stable coronary disease. N Engl J Med 2005;352:1425-35.

[78] Pedersen TR, Cater NB, Faergeman O, Kastelein JJ, Olsson AG, Tikkanen $\mathrm{MJ}$, et al. Comparison of atorvastatin $80 \mathrm{mg} /$ day versus simvastatin
20 to $40 \mathrm{mg}$ /day on frequency of cardiovascular events late (five years) after acute myocardial infarction (from the Incremental Decrease in End Points through Aggressive Lipid Lowering [IDEAL] trial). Am J Cardiol 2010;106:354-9.

[79] Cannon CP, Braunwald E, McCabe CH, Rader DJ, Rouleau JL, Belder $\mathrm{R}$, et al. Intensive versus moderate lipid lowering with statins after acute coronary syndromes. N Engl J Med 2004;350:1495-504.

[80] Cannon CP, Blazing MA, Giugliano RP, McCagg A, White JA, Theroux P, et al. Ezetimibe added to statin therapy after acute coronary syndromes. N Engl J Med 2015;372:2387-97.

[81] Cannon CP, Steinberg BA, Murphy SA, Mega JL, Braunwald E. Metaanalysis of cardiovascular outcomes trials comparing intensive versus moderate statin therapy. J Am Coll Cardiol 2006;48:438-45.

[82] Josan K, Majumdar SR, McAlister FA. The efficacy and safety of intensive statin therapy: a meta-analysis of randomized trials. CMAJ 2008; $178: 576-84$.

[83] Spector R, Snapinn SM. Statins for secondary prevention of cardiovascular disease: the right dose. Pharmacology 2011;87:63-9.

[84] Rubins HB, Robins SJ, Collins D, Fye CL, Anderson JW, Elam MB, et al. Gemfibrozil for the secondary prevention of coronary heart disease in men with low levels of high-density lipoprotein cholesterol. Veterans Affairs High-Density Lipoprotein, Cholesterol Intervention Trial Study Group. N Engl J Med 1999;341:410-8.

[85] Frick MH, Elo O, Haapa K, Heinonen OP, Heinsalmi P, Helo P, et al. Helsinki Heart Study: primary prevention trial with gemfibrozil in middleaged men with dyslipidemia - safety treatment, changes in risk factors, and incidence of coronary heart disease. N Engl J Med 1987;317:1237-45.

[86] Corti MC, Guralnik JM, Salive ME, Harris T, Ferrucci L, Glynn RJ, et al. Clarifying the direct relation between total cholesterol levels and death from coronary heart disease in older persons. Ann Intern Med 1997;126:753-60.

[87] Rubin SM, Sidney S, Black DM, Browner WS, Hulley SB, Cummings SR. High blood cholesterol in elderly men and the excess risk for coronary heart disease. Ann Intern Med 1990;113:916-20.

[88] Houterman S, Verschuren WM, Hofman A, Witteman JC. Serum cholesterol is a risk factor for myocardial infarction in elderly men and women: the Rotterdam Study. J Intern Med 1999;246:25-33.

[89] Simons LA, Friedlander Y, McCallum J, Simons J. Risk factors for coronary heart disease in the prospective Dubbo Study of Australian elderly. Atherosclerosis 1995;117:107-18.

[90] Baigent C, Keech A, Kearney PM, Blackwell L, Buck G, Pollicino C, et al. Cholesterol Treatment Trialists' (CTT) Collaborators. Efficacy and safety of cholesterol lowering treatment: prospective meta-analysis of data from 90,056 participants in 14 randomised trials of statins. Lancet 2005:366:1267-78.

[91] Brugts JJ, Yetgin T, Hoeks SE, Gotto AM, Shepherd J, Westendorp RG, et al. The benefits of statins in people without established cardiovascular disease but with cardiovascular risk factors: meta-analysis of randomised controlled trials. BMJ 2009;338:b2376.

[92] Shepherd J, Blauw GJ, Murphy MB, Bollen EL, Buckley BM, Cobbe SM, et al. PROspective Study of Pravastatin in the Elderly at Risk. Pravastatin in elderly individuals at risk of vascular disease (PROSPER): a randomised controlled trial. Lancet 2002;360:1623-30. 